\title{
ON THE CONVERSION OF A PHOTOGRAPH INTO A LINE DRAWING
}

\author{
WAYNE J. ATWELL \\ From the Department of Anatomy, University of Michigan \\ TWO FIGURES
}

The making of suitable drawings for reproduction has always been a problem, especially in laboratories which do not command the services of a competent artist. The modern recourse to a use of photography and photo-micrography with subsequent reproduction in halftone, while greatly reducing the labor of preparation, has not produced pictures uniformly satisfactory in simplicity and definiteness. Wax models do not readily lend themselves to photographic methods. Photographs of anatomical dissections do not prove sufficiently clear for easy interpretation after having been subjected to the necessary reduction.

The process of line drawing on the other hand leaves nothing to be desired in clearness, since there needs to be depicted only what seems to be essential. Still the execution of suitable drawings from such subjects as those above mentioned requires considerable artistic ability and no little valuable time. As is well known the cost of reproducing photographs and drawings in half-tone is much greater than that of reproducing line drawings in black and white.

With these considerations in mind it has seemed that a means for more generally utilizing the line method would be welcome, if, at the same time, it might be possible to eliminate some of its demands on time and artistic skill.

At the suggestion of Dr. Huber a method which has been in use for many years by commercial artists and engravers, and known as the 'silver print', has been adapted to the use of scientific illustrators.

In brief the method is: 1) To produce a passable negative of the model, dissection or other object to be pictured. 2) Print from this negative an enlargement of suitable size on bromide paper. ${ }^{1}$ 3) Trace outline of print with waterproof ink and fill in shaded portions by stippling, or by a few lines judiciously placed. 4) Bleach out all traces of photograph.

In making the initial negative only the ordinary precautions of careful lighting, proper orientation, etc., are necessary. The conceal-

${ }^{1}$ If the negative is large enough contact prints on cheaper papers, even blue prints, may be used instead of enlargements. 
ing of supporting frames and wires is not required, nor will these need to be removed later by opaquing the background of the negative. A large negative is not necessary, $4 \times 5$ or $5 \times 7$ plates sufficing for most subjects, while for some even $3 \frac{1}{4} \times 4 \frac{1}{4}$ plates will be found large enough.

If the laboratory possesses a 'copying, enlarging and reducing' camera the printing of all sizes of enlargements up to and including $8 \times 10$ inches will be an easy matter. The camera is arranged as ordinarily used in making enlargements or reductions. The spring which usually holds the plate firm in the plate-holder should be removed. The bromide paper is then inserted and supported at the back by one or more sheets of stiff cardboard. If the bromide paper is of fair weight no difficulty will be experienced in keeping it flat and during exposure it may be handled precisely as a dry plate. Of course it will be necessary to select a bromide paper with a smooth surface so that it will later take the pen readily. ${ }^{2}$

When the print has been allowed to dry thoroughly it may be inked in, using of course waterproof India ink. The coarseness of the lines must be proportionate to the amount of reduction which the drawing is later to undergo. At all events the lines and dots must not be too close together. It is best not to try to reproduce all the detail of the photograph.

After allowing the ink to dry, the print is placed first in a tray of water for a few minutes and then transferred to a tray containing the following two solutions in the proportion of eight parts of No. 1 to one part of No. 2.

1. Hypo (thiosulphate of sodium), $30 \mathrm{~g}$.; water, $480 \mathrm{cc}$.

2. Potassium ferricyanide, $30 \mathrm{~g}$.; water, $480 \mathrm{cc}$.

The print should remain in this bath until the last traces of the photograph proper have disappeared, which may require from 20 to 30 minutes. It is best to do this in a dark room. Then after washing for 15 or 20 minutes in running water, the drawing may be dried flat or mounted on card board. Some care is necessary in handling the drawing while wet so as not to rub the surface for the ink is then soft enough to smear.

This method results in the production of a clean drawing, accurate in outline, and with the shade correctly placed so that perspective should be properly brought out.

The accompanying figures show a model of the hypophysis region of a chick embryo reproduced by both half-tone and line etchings, the latter prepared by the method here described.

2 This laboratory has successfully used the 'P.M.C.' bromide paper in 'Smooth' and 'Glossy' surfaces (Nos. 2 and 4) made by the Eastman Kodak Company. 

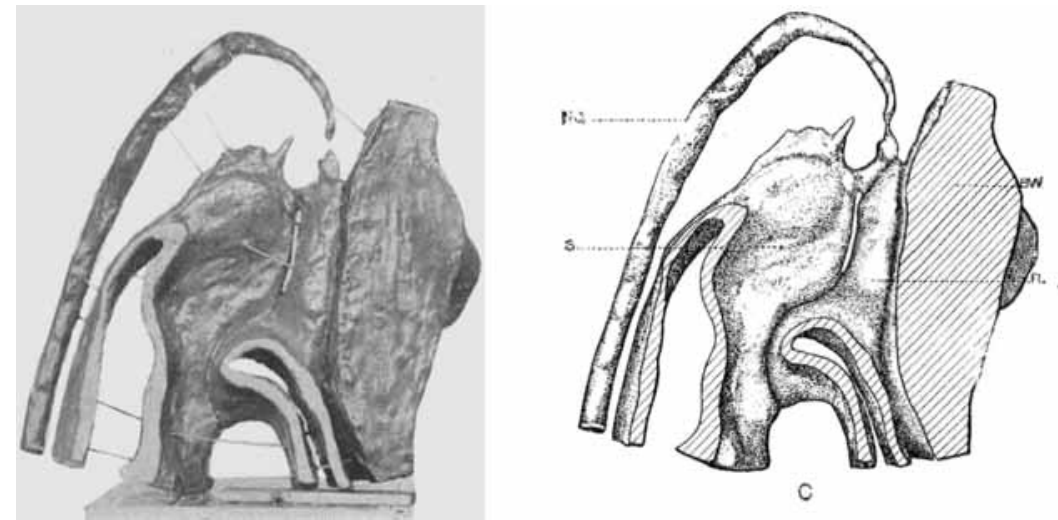


\section{A CORRECTION-R. W. SHUFELDT}

At the time I was preparing my article on the "Comparative osteology of certain rails and cranes, and the systematic positions of the super-suborders Gruiformes and Ralliformes," which appeared in the October issue of The ANatomical Record (Vol. 9, No. 10, pp. 731$750,1915)$, I had before me two manuscripts, namely the old one, published many years ago, when I considered that the Aramidae was a family belonging among the cranes and their allies (Gruiformes), and the remodeled one, in which my present views were set forth. In assembling the pages, the old page upon which the classification and some of the remarks under 'conclusions' appeared, was accidentally substituted for the new one carrying the new classificatory scheme upon it. In this shape it was handed over to be typewritten. When galley proof came to hand, I was extremely busy with other work, and it was therefore turned over to an expert proofreader and most carefully corrected. This proofreader knew nothing of the classification of birds, however, and so the galleys went forward, with the result now to be found on pages 749,750 . In so far as my present views are concerned, with respect to the position of the Aramidae in the system, they are correctly set forth in The Anatomical Record of August 20, 1915 (Vol. 9, No. 8, pp. 591-606). 